\title{
Review of Recent Developments and the Future Prospective in West African Atmosphere/Land Interaction Studies
}

\author{
Yongkang Xue, ${ }^{1,2}$ Aaron Boone, ${ }^{3}$ and Christopher M. Taylor ${ }^{4}$ \\ ${ }^{1}$ Department of Geography, University of California, Los Angeles, CA 90095, USA \\ ${ }^{2}$ Department of Atmospheric and Oceanic Sciences, University of California, Los Angeles, CA 90095, USA \\ ${ }^{3}$ Meteo-France, CNRM, Toulouse, France \\ ${ }^{4}$ Centre for Ecology \& Hydrology, Crowmarsh Gifford, Wallingford, Oxon OX10 8BB, UK \\ Correspondence should be addressed to Yongkang Xue, yxue@geog.ucla.edu
}

Received 29 June 2011; Accepted 3 January 2012

Academic Editor: Andrea Sealy

Copyright () 2012 Yongkang Xue et al. This is an open access article distributed under the Creative Commons Attribution License, which permits unrestricted use, distribution, and reproduction in any medium, provided the original work is properly cited.

This paper reviews West African land/atmosphere interaction studies during the past decade. Four issues are addressed in this paper: land data development, land/atmosphere interactions at seasonal-interannual scales, mesoscale studies, and the future prospective. The development of the AMMA Land Surface Model Intercomparison Project has produced a valuable analysis of the land surface state and fluxes which have been applied in a number of large-scale African regional studies. In seasonalinterannual West African climate studies, the latest evidence from satellite data analyses and modeling studies confirm that the West African region has a climate which is particularly sensitive to land surface processes and there is a strong coupling between land surface processes and regional climate at intraseasonal/seasonal scales. These studies indicate that proper land surface process representations and land status initialization would substantially improve predictions and enhance the predictability of West African climate. Mesoscale studies have revealed new understanding of how soil moisture heterogeneity influences the development of convective storms over the course of the diurnal cycle. Finally, several important issues regarding the future prospective are briefly addressed.

\section{Introduction}

West Africa is a diverse climatic region that includes a semiarid tropical zone in its northern section and a humid tropical climate zone in its southern section. Today, it is a bioclimatic zone of predominantly annual grasses with shrubs and trees, receiving a mean annual rainfall of between 150 and $2500 \mathrm{~mm}$ per year (Figure 1(a)). According to the United Nations' definition [1], it includes 16 African countries and covers an area in excess of approximately 6 million $\mathrm{km}^{2}$. Its northern boundary is along the southern margin of the Sahara Desert, with the Atlantic Ocean to its west and to its south. There is no consensus on its eastern boundary, which is commonly specified using a line running from Mount Cameroon to Lake Chad. The elevation of the vast majority of this land is less than 300 meters above sea level, though isolated points of higher elevation exist in several countries along the southern shore of the region.
West Africa has experienced significant climate anomalies in the past century. Its northern section, which is referred to as the Western Sahel, suffered the most severe and longest droughts in the world during the twentieth century. Annual rainfall has persistently remained below the longterm average since the late 1960s, with devastating droughts during the late 1960s and the early 1980s (Figures 1 (b) and 1(c)) [2-5]. Starting from the late 1980s, however, there has been some rainfall recovery relative to the very dry period (Figures 1(b) and 1(d)). A study by Lau et al. [6] finds that there has been an increase in the "continentality" of the West African monsoon (WAM), reflected by a shift of the WAM convection towards land from the later 1980s to the 1990s and the 2000s. The hydrologic variability in West Africa shows one of the strongest interdecadal signals worldwide during the 20th century [7]. There has been rapid population growth in the region over the past 50 years [8]. The severe droughts and resulting famines have devastating 


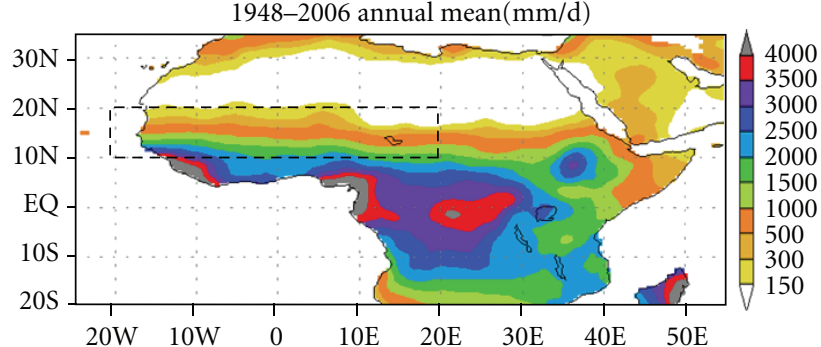

(a)

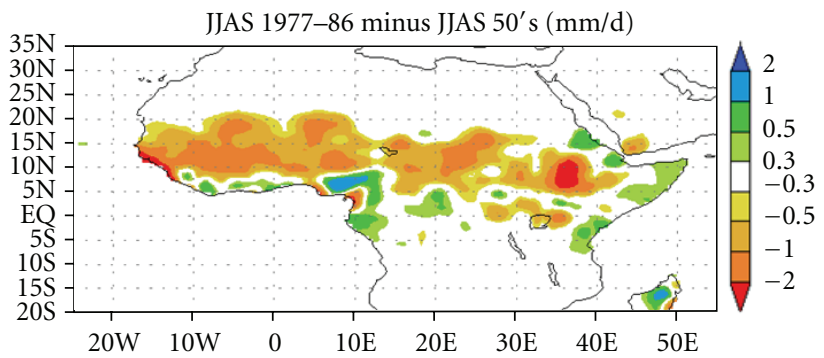

(c)

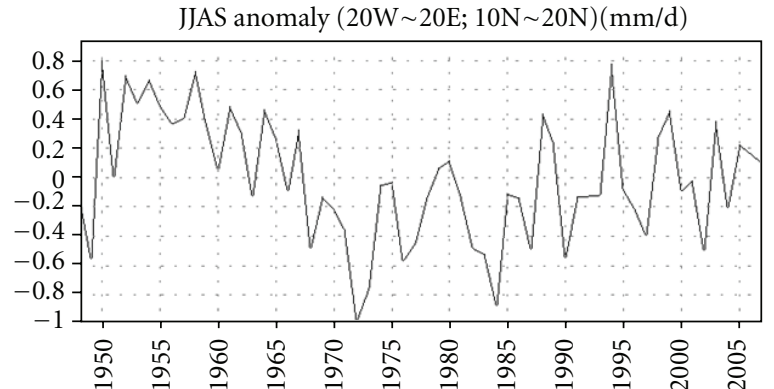

(b)

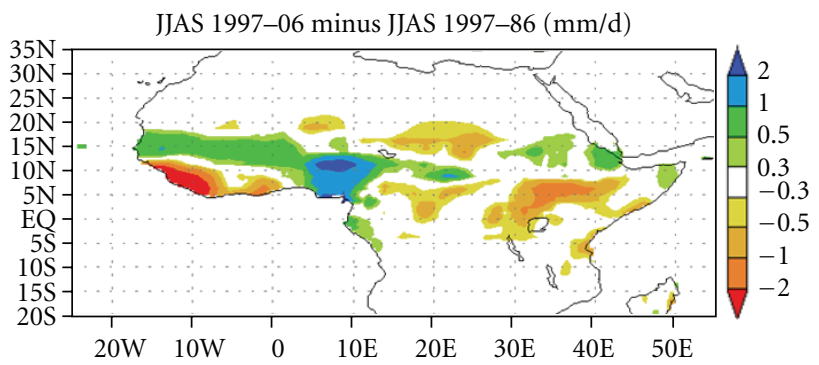

(d)

Figure 1: (a) Observed climate annual mean precipitation $\left(\mathrm{mm} \mathrm{day}^{-1}\right)$; (b) time series of June-July-August-September (JJAS) mean precipitation $\left(\mathrm{mm} \mathrm{day}^{-1}\right.$ ) averaged over $20^{\circ} \mathrm{W}$ to $20^{\circ} \mathrm{E}$ and $5^{\circ} \mathrm{N}$ to $20^{\circ} \mathrm{N}$ (the box outlined in (a)); (c) observed JJAS precipitation difference $\left(\mathrm{mm} \mathrm{day}^{-1}\right.$ ) between the 1980s and the 1950s; (d) observed JJAS precipitation difference (mm day ${ }^{-1}$ ) between 1996-2006 and $1976-1987$. Data Sources: National Center for Environmental Prediction Climate Prediction Center Merged Analysis of Precipitation (CMAP, [23]).

environmental and socioeconomic consequences, which, along with the scientific challenge to understand causes of such extraordinary drought and climate variability, have presented a strong motivation for the scientific community to study West African climate variability and causes of Sahel drought, most of which occurred in West Africa. The term "Sahel drought" will be used interchangeably with "West African drought" in this paper. The Sahel drought is known to be strongly influenced by sea surface temperature (SST) anomalies, both globally and in regions adjacent to the African continent $[9,10]$. Meanwhile, land surface processes, including the land use and land cover (LULC) change, have also been extensively investigated as one of the major factors influencing the West African climate system, which is the focus of this paper.

There is a steep latitudinal gradient in climate, soils, vegetation, fauna, land use, and human utilization, with strong correlations among them [11]. The continental-scale land mass and relatively flat orography suggests that landsurface/atmosphere interactions play a major role in the regional climate. From the mid-1970s through the 1990s, numerous studies have been conducted to explore the impact of the land surface on the West African climate. Modeling studies with different levels of complexity in their atmospheric models and land surface parameterizations have consistently suggested that the Sahel is one of the regions in the world where the land/atmosphere feedback plays an important role in regional climate variability, and LULC may be an important contributing factor to the persistent Sahel drought [12-20]. Comprehensive reviews on the relevant
land/West African climate research mainly before the 21 century were summarized in Xue et al. [21].

There are several important characteristics in land/West African climate research reviewed in [21]. (1) Most studies test the sensitivities of regional climate to a few land parameters, such as surface albedo and soil moisture, explicitly or implicitly with LULC change embedded in the experimental designs. Only recently, encouraged by those early sensitivity studies, have more sophisticated vegetation models been introduced in West African climate studies (2) The Sahel drought was the main motivation for those studies. Most studies were conducted using either $3 \mathrm{D}$ or $2 \mathrm{D}$ coupled atmosphere/land surface models to estimate the possible land contribution to the drought. (3) There were only a few measurements over very few sites. Due to the limited availability of observational data over the West African region at that time, validation of the land models for regional climate and hydrological cycle study was largely missing. However, these research efforts have established a consensus in the public and part of the meteorological community that, in addition to SST, land surface processes are an important component affecting the West African regional climate, thereby stimulating more extensive research in this field.

In the past decade, important developments for obtaining a better understanding of the West African monsoon (WAM)/land interaction at intraseasonal/interannual/ interdecadal scales have been made, in particular under the African Monsoon Multidisciplinary Analysis (AMMA) Project [22]. We will discuss a few major issues and 
achievements in the West African climate and land process interaction study in the past decade in this paper. In Section 2, new land data development for the WAM study and its application are presented. Section 3 focuses on the land/West African climate interactions studies at seasonal, interannual, and decadal scales. Section 4 discusses mesoscale interactions, and Section 5 presents a summary and future prospective in this field.

\section{Land Data Development for the West African Monsoon Study and Its Application}

Modeling the West African monsoon has proven difficult mainly due to both the paucity of observations at sufficient space-time resolutions, and because of the complex interactions of the relevant processes between the biosphere, atmosphere, and hydrosphere over this region. Distinct from the previous observational efforts which encompassed only one or a few sites [24], the AMMA program has organized comprehensive activities in data collection in order to increase the understanding and improve the modeling of the WAM/land interactions over a wide range of spatial and time scales [7]. A comprehensive review of AMMA field campaigns' key accomplishments and lessons learned from the extraordinary efforts made by a community of several hundred researchers has been discussed by Lebel et al. [25] .

The application of observations from many local sites for large-scale atmosphere/land interaction study is always a challenge due to scale discrepancy. The AMMA Land Surface Model (LSM) Intercomparison Project (ALMIP; [26]) addresses this issue. In ALMIP, a set of state-of-theart off-line land surface models (uncoupled from their host atmospheric models) have been forced with the best quality and highest space and time resolution data available to better understand the key processes and their corresponding scales. The forcing consists of a combination of shortterm numerical weather forecast low-level atmospheric state variables, satellite-based rainfall (such as the Tropical Rainfall Measuring Mission (TRMM, [27]), and downwelling radiation flux products (Land-Satellite Application Facility; [28]), and data from the AMMA observational field campaigns. The ALMIP LSM outputs for the period 2002-2007 have been compared with satellite-derived surface brightness temperature [29], satellite-based soil water storage estimates [30], and observed turbulent fluxes [26]. In the evaluation, the site turbulence measurements were first upscaled to the ALMIP mesoscale grids for comparison [31].

Overall, there is a good LSM intermodel agreement. For example, the predicted latent fluxes agree well with a coefficient of variation ranging from approximately 5 to $15 \%$ over most of West Africa, with the best agreement over the semiarid Sahel where the vast majority of rainfall is subsequently reevaporated at the land surface. The ALMIP LSM-predicted surface fluxes and thermal and hydrological state variables at the land surface are akin to a multimodel surface reanalysis product. Studies [32] have shown the advantages and improved realism of using a multi-LSM model average of simulated surface properties. The ensemble signal to noise ratio of the surface turbulent fluxes is fairly large (approximately 0.7 to 0.9 ) over most of the region [33].

Because the ALMIP data cover most of West Africa, this data set can be considered as one of the best currently available proxies for large-scale estimates of the land surface state over West Africa for different applications. For example, ALMIP results have been used for a number of mesoscale to regional scale case studies within AMMA, such as the study of feedbacks between dust emissions and the atmosphere $[34,35]$, and the regional atmospheric nitrogen balance [36]. Results have also been used to examine the influence of initial soil moisture on medium range weather prediction at the European Centre for Medium-Range Weather Forecasts (ECMWF; [37]). In addition, ALMIP results have been recently used for evaluating the land surface component of numerical weather prediction (NWP) and mesoscale models [38], regional climate models (RCMs, [39]), and general circulation models (GCMs, [40]). Moreover, regional scale water budget estimates have been made [41] using ALMIP surface evaporation fluxes.

The application of the ALMIP products in the West African Monsoon Modeling and Evaluation (WAMME) project [42] clearly demonstrated its utility in the largescale African land/atmosphere interaction studies [33]. It was found that simulated net radiation within WAMME GCMs and RCMs generally agrees rather well with ALMIP. However, the partitioning of this energy into turbulent fluxes is different from ALMIP and is quite variable. This seems to be due, in part, to further northward placement of the monsoon in areas and positive precipitation bias with larger potential energy for evaporation in most of the WAMME models. Furthermore, ALMIP produces the maximum latent heat flux during the monsoon retreat as stored water is evaporated before solar radiation reaches the boreal winter minima; only 6 of the WAMME models have this feature, and it is generally rather weak. These features are summarized in the Hovmoller plot in Figure 2, where WAMME model simulated latent heat fluxes are compared to those from ALMIP for 2004 averaged over the region from $-10^{\circ}$ to $10^{\circ} \mathrm{E}$ latitude, and the southern coast of West Africa to $20^{\circ} \mathrm{N}$. Finally, in contrast to ALMIP results and local scale observations which indicate values on average of the meridional ratio of sensible heat flux to the net radiation to be approximately 0.35 , the ratio becomes quite low (generally less than 0.10 ) from the Sahel to the southern coast of West Africa during the core monsoon season for nearly all of the WAMME models. All these findings should help identify weaknesses in current West African climate modeling, understand the WAM mechanisms, and contribute to further model development.

By and large, ALMIP provides a robust regional scale estimate of land surface state variables and fluxes from an ensemble of state-of-the art land surface models in its first phase experiment. Satellite-based data (GRACE, AMSR-E, etc.) were introduced for evaluation of ALMIP data. ALMIP data address many key science issues within AMMA, such as how coupled models simulate the land states and fluxes and obtain better estimates of the regional scale water budget. The development of the data was a major achievement in the 


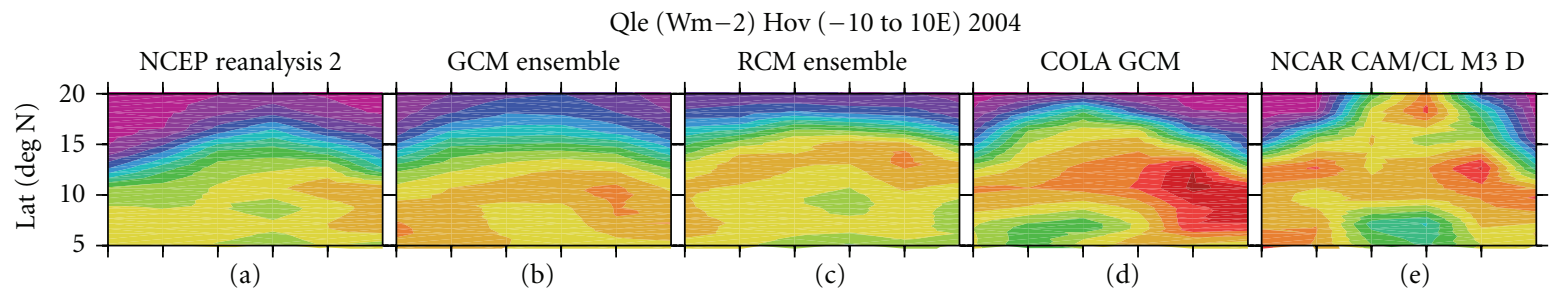

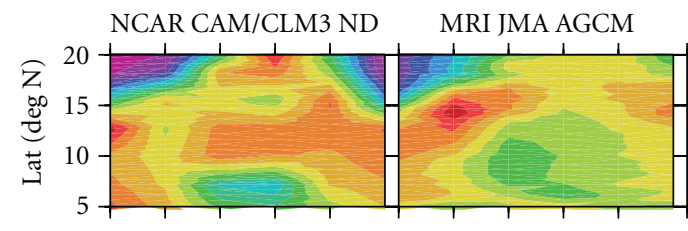

(f)

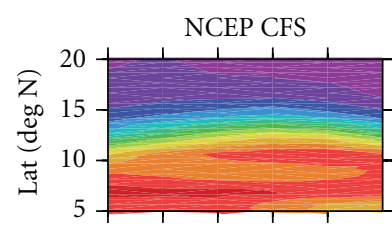

(k) (g)

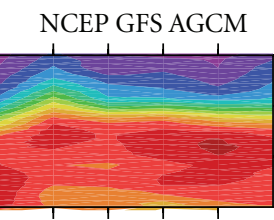

(1)

NASA GSFC GMAO

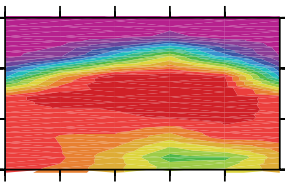

(h)

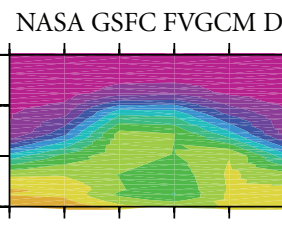

(i)

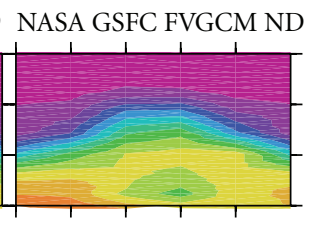

(j)

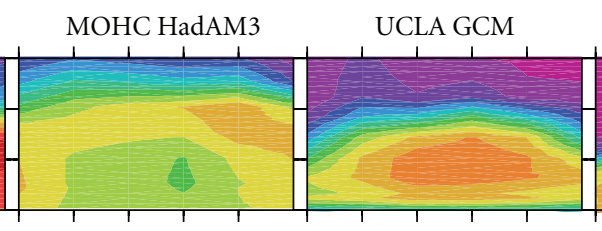

(m)

(n)

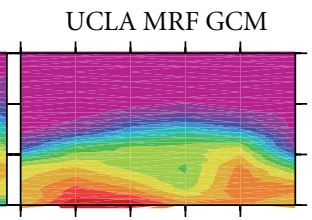

(o)

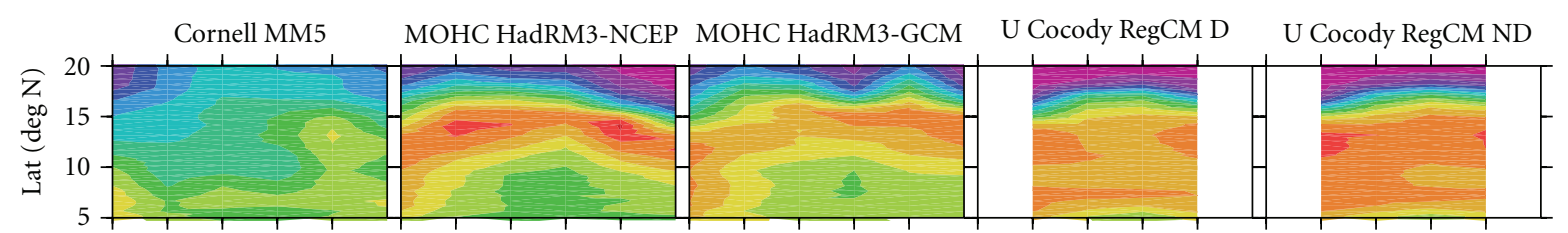

(p)

(s)

$(\mathrm{t})$

(u)

(v)

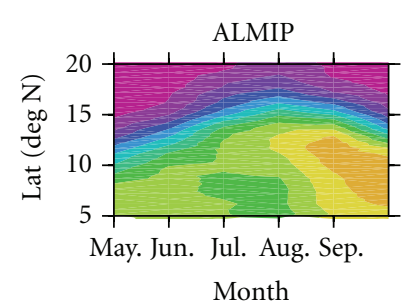

(w)

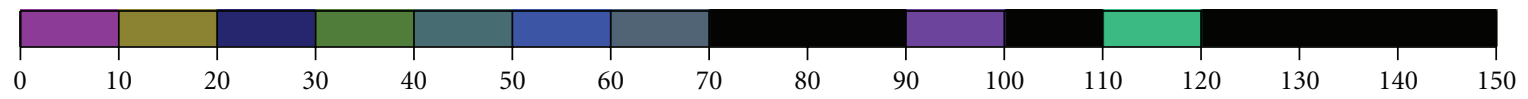

FIGURE 2: The WAMME latent heat flux area averaged from June through September (JJAS) for 2004 [33]. The corresponding ALMIP field is shown in panel $(\mathrm{w})$.

past decade, which should pave the way for more scientific understanding in Sahel climate and its relationship with land surface processes and LULC change.

\section{Seasonal and Interannual West African Climate Variability and Land Surface Processes}

In the past decade, studies of West African climate/land interaction have focused primarily on predictability and prediction, that is, whether introducing adequate land surface processes improves the simulation of West African climate and enhances its predictability at different scales and possible mechanisms. The West African climate is dominated by the WAM system. Monsoon circulations are forced and maintained by sea-land thermal contrasts and by latent heat released into the atmosphere. Therefore, the WAM/land interaction was a major issue in these studies.

Insufficient data was a major obstacle to the evaluation of model-produced land/atmosphere interactions. Numerous remotely sensed products have become available during the past decade. Some derived satellite products, such as the Normalized Difference Vegetation Index (NDVI) and the fraction of photosynthetically active radiation (FPAR), have been considered to be observed measures of green vegetation condition. Analyses of these satellite products and climate data have confirmed a close relationship between 
vegetation conditions and precipitation at different scales [43-46], which early on was only suggested by modeling studies. For example, Martiny et al. [43] found that, in the southern Sahel, annual NDVI was highly correlated to annual precipitation of the concurrent year and the previous year. In another study with a statistical model of vegetation greenness [46], the results suggested a positive feedback between vegetation and Sahel rainfall at the monthly time scale and a vegetation memory operating at the annual time scale. This study suggests the previous year's vegetation growth affects greenness in the following year.

The statistical model also found that these vegetationrainfall interactions increased the interannual variation in Sahelian precipitation, accounting for as much as $30 \%$ of the variability in annual precipitation in some sub-Sahel regions between $15^{\circ}$ and $20^{\circ} \mathrm{N}$. Furthermore, the seasonal differences had also been noted in some studies. For example, Liu et al. [45] found that, in the Sahel region the FPARlead correlations with precipitation are positive in spring and summer but become negative in fall and winter. Moreover, the trends and variability of these satellite-derived products and their major modes were also the subjects of some diagnostic studies [47-49]. Studies have revealed an increase in NDVI/LAI (leaf area index) and a decrease in surface albedo over the Sahel during the period 1982-1999 [50-52] that are interpreted as a vegetation recovery from the very dry periods of the 1980s.

Despite limitations in these types of studies due to data quality and data processing errors, short in duration, robustness in statistical approaches used, and uncertainty in using satellite products to represent real vegetation conditions, these results, nevertheless, shed light on the real vegetation/atmosphere interaction and provide a new and valuable reference for evaluating model-simulated vegetation/atmosphere interactions.

Meanwhile, modeling studies have shown more evidence that land/atmosphere interactions have profound effects on the WAM system at different scales. In a Global LandAtmosphere Coupling Experiment (GLACE) study [53] investigating soil moisture/atmosphere coupling strength with multiple general circulation models (GCMs), each model conducted several ensembles of boreal summer (June through August) simulations: in one ensemble of 16 simulations, soil moisture varied with the simulations, while in another ensemble, the specified geographically varying time series of subsurface soil moisture was forced to be the same across the 16 simulations. If the model-simulated precipitation does not respond to soil moisture, the precipitation difference between these two ensembles should be very little. Soil moisture/atmosphere coupling strength of each model then was estimated based on each model's two ensembles with a statistical method. Figure 3 shows the global map of the difference averaged across twelve of the participating models, with higher values implying a higher impact of the soil moisture conditions on precipitation. This multiple model estimation of land atmosphere coupling strength reveals that the Sahel, along with a few other regions,
Land-atmosphere coupling strength, averaged across models

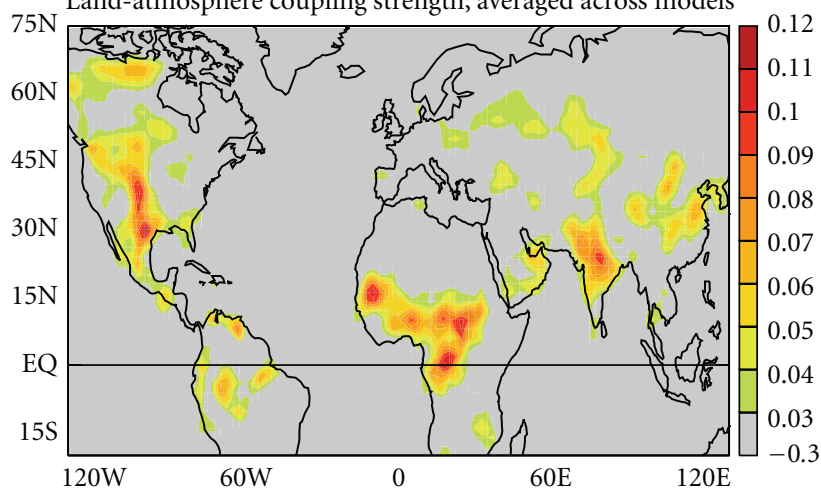

FIGURE 3: The soil moisture-atmosphere coupling strength diagnostic for boreal summer (the difference, dimensionless, describing the impact of soil moisture on precipitation), averaged across the 12 participating models. Courtesy by Dr. Randy Koster of NASA based on Koster et al. [53].

most of which lie along ecotones associated with semiarid areas, has the greatest soil moisture/climate coupling strength in the world.

The GLACE results are consistent with other soil moisture feedback studies. For instance, Douville et al. [54, 55] found that the proper simulation of the African monsoon required adequate soil moisture information, such as the soil moisture data from the Global Soil Wetness Project [56]. Using the Intergovernmental Panel on Climate Change IPCC models' simulation results, Notaro [57] also identifies North Africa as a region with strong soil moisture feedback. Furthermore, Philippon and Fontaine [58] proposed a soil moisture/monsoon regulation mechanism in which September to November Sahelian rainfall of the previous year could influence July to September Sahelian rainfall. However, other modeling studies $[59,60]$ showed that the root-zone soil moisture did not act as a memory of rainfall anomaly that would produce an effect into the following rainy season, and, therefore, it is not found to be related to the long-term persistence of the drought. A study using a regional climate model [61] found that the role of surface conditions in the precipitation dynamics is generally not overwhelming, even under conditions where soil moisture exerts a significant influence on surface evaporation. During the heart of the wet seasons in the Sahel, soil moisture is abundant and hardly constraining evaporation, precluding a strong landatmosphere coupling. In addition, Koster et al. [53] also show that, although the average over 12 participating models' simulations indicate the Sahel area had higher coupling strength, substantial discrepancies among models existed. Further investigation on the soil moisture issues is warranted.

The impact of the vegetation biophysical process (VBP) on the WAM is another important subject under investigation. VBP refers to those land surface processes relevant to climate interactions associated with vegetation [62]. Xue et al. [62] analyzed two GCMs coupled to three different land models with varying degrees of physically based complexity in the representation of VBP. The importance of VBP effects 


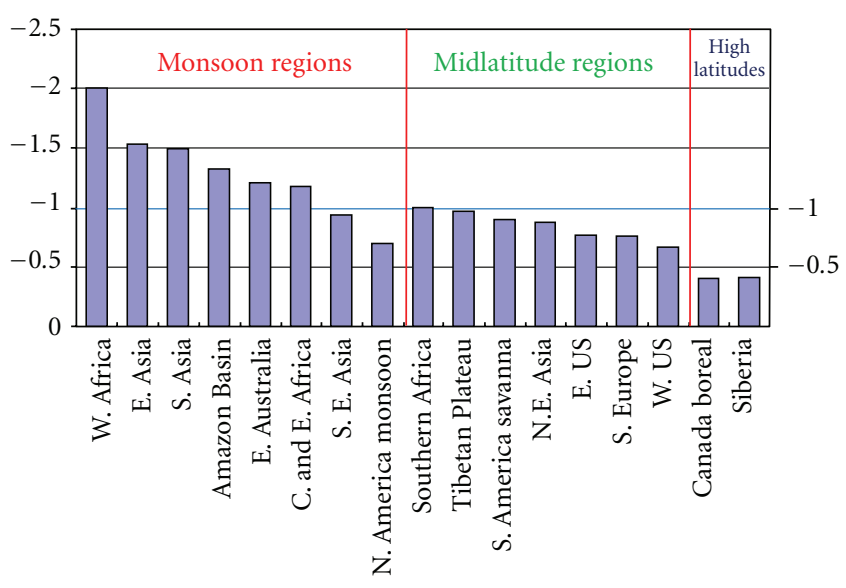

FIGURE 4: Reduction of absolute annual mean precipitation bias $\left(\mathrm{mm} \mathrm{day}^{-1}\right)$ due to vegetation biophysical processes for different regions, indicating the impact of vegetation biological process on precipitation [62]. Differences of absolute bias of annual mean precipitation $\left(\mathrm{mm} \mathrm{day}^{-1}\right)$ between LA-VBP and LA-VBP.

on climate were assessed based on the skill of simulations of observed global precipitation by two GCMs with different land models. Since a more realistic representation of VBPs in a GCM should improve precipitation simulations if VBP has effects on the real climate system, the statistically significant reduction of absolute bias and root-mean-square errors (RMSE) between simulated precipitation and the observation was adopted as criteria to identify VBP effects. Figure 4 shows the reduced absolute annual mean bias of 5year precipitation simulations (or improved prediction skill) due to VBP process in the GCM. West Africa again shows the largest impact in the world. Further analyses revealed that, in West Africa, land surface processes have the most impact during the summer and the fall, with some impact during spring. The VBP's importance for the WAM has also been demonstrated by the application of satellite-derived vegetation products, such as LAI and vegetation coverage. By using remotely sensed LAI datasets, compared with using LAI based on a few ground surveys, the GCM produced substantial improvements in the near-surface climate in a few summer monsoon areas, including West Africa [63].

In addition to the seasonal mean, the land effect on the intraseasonal climate variability at large-scales was also a subject for some modeling studies [39, 64-66]. The studies showed that vegetation properties played a significant role in the intraseasonal variations of precipitation and circulation over West Africa [64], and intraseasonal soil moisture fluctuations were intense enough to feed back on the lowlevel vorticity structure [65]. In another study with a regional model, it has been shown that with a more realistic VBP representation, the seasonal timing and magnitude of mean monsoon precipitation more closely match observations, especially the timing of the monsoon advance and retreat across the Guinean Coast. In addition, the migration and position of the African Easterly Jet more closely match reanalysis winds [39].

The mechanisms for land surface/atmosphere interactions on the WAM, especially with respect to precipitation and the important WAM feature-African Easterly Jet (AEJ), have also been examined by a number of studies. When the atmospheric temperatures below the mid-troposphere are higher to the north (i.e., over the Sahara) and lower to the south, meridional temperature gradients are positive over tropical West Africa, and, according to basic atmospheric circulation thermodynamics principles, the thermal wind (and hence the jet) is easterly. The maximum latitudinal temperature gradient, which is related to the hot, dry surface conditions and a deep, well-mixed boundary layer in the Sahara heat low and cool, moist surface conditions associated with deep moist convection in the intertropical convergence zone, is associated with the strongest easterly thermal wind and therefore the AEJ in the mid-troposphere [67-69]. Wu et al. [70] suggest that it is not only the evaporation gradient that highly correlated with soil moisture, but a combination of vegetation properties and orography is also essential for the maintenance of the mean climatological AEJ. Therefore, it is the very particular combination of moisture gradients, vegetation distribution, and orography that produces the $\mathrm{AEJ}$, not the soil moisture gradients alone.

Modeling studies further demonstrate the close relationship between the meridional thermal gradient, AEJ, and WAM precipitation and its onset. In the WAMME first experiment, 11 GCMs have been integrated from April through October with multiple members [42]. Common empirical orthogonal functions (CEOF) analysis based on observational data and multimodel simulation results was applied to characterize the major WAM features and has identified that the PC1 of precipitation and PC1 (Sahara mode) and PC2 (Sahel mode) of surface temperature characterize the WAM precipitation evolution and the northward movement of temperature gradient, respectively, and the WAM precipitation northward movement/retreat is closely associated with the weakening/enhancing of the Sahel mode (temperature PC2) and the enhancing/weakening of the Sahara mode (temperature PC1), which in turn enhances/weakening the meridional temperature gradient. The speed of the WAM evolution and the position of the WAM precipitation band are closely related to the development of this thermal gradient. The study identifies a close relationship between WAM onset and thermal low development in the Sahara: the timing of monsoon onset is about 10-15 days after the peak of the summer temperature anomaly in the Sahara.

Analyses further show that spatial distributions of surface sensible heat flux, surface temperature, and moisture convergence were closely associated with the simulated spatial distribution of precipitation; while surface latent heat flux is closely associated with the AEJ [42]. All these indicate the important role of the land surface energy partitioning in the WAM system, especially the thermal effect and surface induced large-scale circulation change as indicated by the moisture flux convergence change. 


\section{Mesoscale Circulation Variability and Land Surface Processes}

Observations indicate high spatial heterogeneity of surface vegetation and soil conditions in the Sahel area [71]. Results from AMMA have provided new understanding of how this heterogeneity influences the development of convective storms over the course of the diurnal cycle. Because evaporative demand is high and the vegetation is sparse across the Sahel, particularly early in the wet season, the surface energy balance is strongly influenced by the availability of soil moisture close to the surface [72]. Rain events create strong mesoscale variability in soil moisture, and the resulting patterns of sensible and latent heating have been found to play an important role for the development of new storms during the afternoon in a number of studies.

Using land surface temperature data from satellite as a proxy for soil moisture (wet surfaces are up to $10 \mathrm{~K}$ cooler than dry surfaces), aircraft flights during AMMA were targeted at areas containing wet and dry soils. Taylor et al. [73] found that the temperature within the convective boundary layer during the afternoon was significantly correlated with the land surface temperature (i.e., anticorrelated with soil moisture) for surface features as small as $2.5 \mathrm{~km}$ and, furthermore, found a clear correlation between surfaceinduced temperature gradients and the low-level winds. Further evidence for mesoscale circulations induced by the land was presented over forest-crop transitions [74].

Numerical model experiments have shown how surfacedriven convergence provides a favored location for the initiation of deep convection $[75,76]$. The importance of this feedback mechanism has been highlighted in a recent study by Taylor et al. [77] analyzing nearly 4000 storms from satellite data of clouds and antecedent land surface temperature. Through detailed tracking of Mesoscale Convective Systems (MCS) with cloud-top temperature back to the location where the first deep cloud appeared, they were able to examine the relationship between the spatial structure of soil moisture and the probability of convective storm initiation. They found that, compared to a homogenous surface, storm initiation was twice as likely to occur $10 \mathrm{~km}$ upwind of a transition from dry to wet soils. This result is consistent with numerical modeling studies $[75,76]$, where contrasts in sensible heat flux drive a circulation which creates maximum low-level convergence where the surface-driven component opposes the large-scale flow (Figure 5). The study estimated that this effect was important for 1 in 8 MCS initiations in the region and implies a nontrivial impact of spatial scale on the sign of the soil moisture-precipitation feedback. Storms tend to initiate over dry soil (a locally negative feedback), but the occurrence of previous rain to create the heterogeneity is a prerequisite for this feedback. The MCS then travels, often many hundreds of kilometers, in turn creating new heterogeneity and favoring more initiations in subsequent days. This implies a positive feedback on the scale of the MCS, $\sim 100 \mathrm{~s} \mathrm{~km}$. Similar mesoscale processes are likely to be responsible for favored initiation of MCS around extensive wetland areas such as the Niger Inland Delta [78].

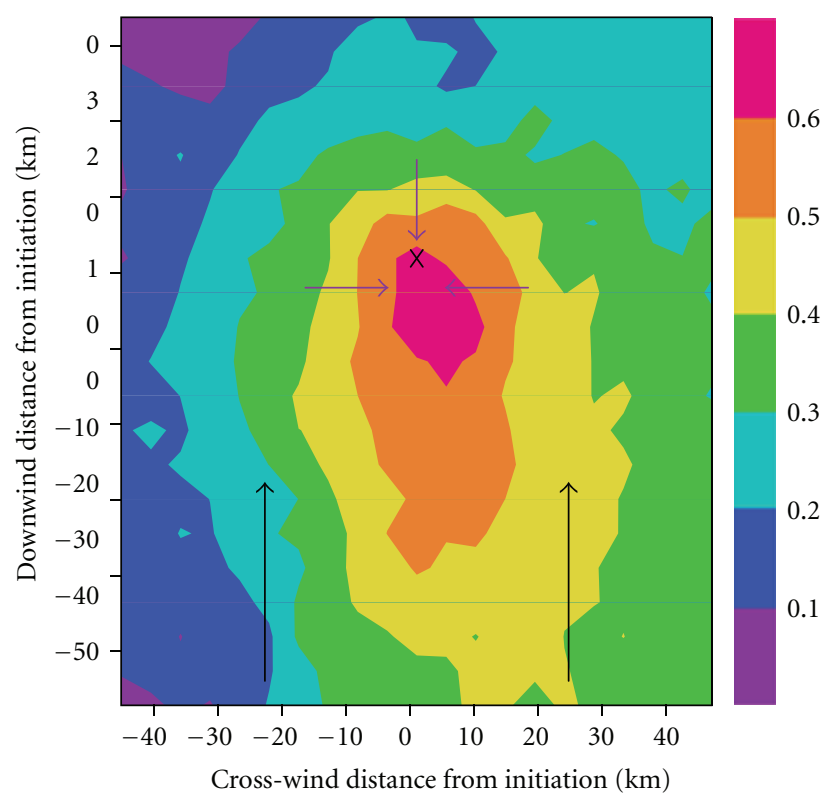

FIGURE 5: Favoured location (X) for initiation of convective storms [77]. Storms tend to develop over locally warm surfaces (shading denotes land surface temperature anomalies $(\mathrm{K})$ based on a composite of nearly 4000 cases), but close to wetter (cooler) soils downwind. Arrows in mauve and black denote, respectively, the surface-induced, and large-scale components of the wind.

Once MCS has developed, various processes may govern the strength, and even the sign, of feedbacks between soil moisture and individual storms [22]. Gantner and Kalthoff [76] show that mature MCS with well-developed gust fronts can intensify over wet soils due to increased convective available potential energy, consistent with an observational case study from AMMA [72]. However, this positive feedback may reverse depending on the phase of the diurnal cycle, the convective inhibition and synoptic state, and the scale and orientation of the wet patch relative to the large-scale flow [75].

\section{Summary and Future Research Prospective}

Based on numerical sensitivity studies using land models with different complexity, conducted from the late 1970s to the 1990s, it has been recognized that, in addition to SST, land surface processes are an important component affecting the West African regional climate, thereby stimulating more extensive research in land/atmosphere interactions for the region. During the past decades, AMMA has conducted extensive large-scale field measurements over the West Africa. Taking the advantage of this unprecedented effort, the ALMIP has produced a valuable analysis of the land surface state and fluxes which has been applied in a number of largescale African regional studies.

Meanwhile, the latest evidence from satellite data analyses and modeling studies confirm that the West African region has a climate which is particularly sensitive to land surface processes and there is a strong coupling between 
land surface processes and regional climate. It has been found that, in addition to the sea/land thermal contrast, the development of the West African monsoon is also closely associated with the evolution of a thermal gradient between the Sahara and southern Sahel. The variations of the West African climate system are closely associated with the surface energy partitioning. Mesoscale studies have revealed new understanding of how soil moisture heterogeneity influences the development of convective storms over the course of the diurnal cycle. The strong coupling between convective storms and soil moisture on time scales associated with soil drying (a few days) suggest that considerable progress could be made in short-term prediction of rainfall. All these studies indicate proper land surface process representations and land status initialization would substantially improve predictions and enhance the predictability of West African climate.

Despite this progress, some key scientific issues still remain. Recent observational evidence has supported the notion that there are strong decadal climate variabilities in the Sahel and surrounding areas from the 1950s to the 2000s, not only in precipitation, but also in SST, vegetation cover, land use and land cover (LULC) change, and aerosol types and spatial distributions. Understanding of the complex interactions of the WAM/Sahel precipitation variability associated with SST and land surface and aerosol forcings is still lacking. Further multimodel intercomparison experiments have to be carried out to improve understanding of the possible feedback to SST, land use change, vegetation, and aerosol forcings at seasonal to decadal scales. Given the complexity of the WAM/Sahel precipitation variability associated with these forcings and their interactions, it is imperative to gain basic understanding of the contribution/roles of land surface process relative to other forcings on the regional water cycle of the Sahel, to assess the relative contributions of land and its interaction with other forcings in producing/amplifying the Sahelian seasonal and decadal climate variability, and to understand the mechanisms involved. For instance, Koster et al.'s study [53] and Xue et al.'s [62] study show consistence and discrepancies in soil moisture and VBP effects on the West African monsoon. It is important to further explore the mechanisms behind. Furthermore, there are a few issues that have to be carefully and adequately addressed.

The influence of LULC change on West African drought was the focus of early land/atmosphere interaction studies (see references listed in Section 1). However, due to the controversy in terms of the degree and extent of land degradation there, the assessment of its realistic impact on the West African climate variability is still an outstanding issue. An early study [79] defined the desertification in the Sahel as the expansion of the Sahara Desert. Given the lack of evidence from satellite observations for the expansion of the boundary of the Sahara desert [80], the notion of Sahel land degradation has been discredited even in a very recent study [46]. A LULC change map even shows there were no noticeable LULC change in West Africa since 1870, which may lead to underestimation of its effect in the region [81]. In fact, studies have indicated that land degradation in West Africa is like "patches," which tends to be localized around settlements [82-84]. Based on a ground surveys,

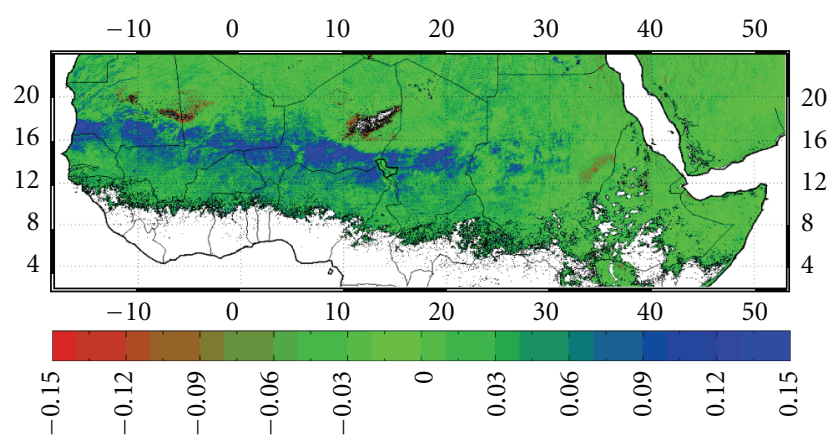

Figure 6: Mean August-September-October broadband surface albedo absolute difference between year 1984 and 2003 over the Sahel region. Missing data are shown in white. Courtesy by Dr. Yves Govaerts of EUMETSAT Based on Govaerts and Lattanzio [51].

Hiernaux et al. [85] found that the overall trend in land use in southwest Niger confirmed the historical increase of the cropped areas since mid-20th century, at an annual rate of $2 \%$ from 1994 to 2006. A recently compiled historical landuse data also indicate substantial land-use conversion over West Africa [86], consistent with dramatic population gains across West Africa. Furthermore, more accurate and highresolution assessments of land condition data start to provide quantitative measurement of land condition change in this region.

For example, Govaerts and lattanzio [51] used the data from the Meteosat spacecraft to compare the derived surface albedo over Sahel from a dry year (1984) and a wet year (2003). They found that, between $12^{\circ} \mathrm{N}$ and $18^{\circ} \mathrm{N}$, the mean August-September-October surface albedo decreased by about 0.06 with a mean zonal difference as large as 0.08 at $16^{\circ} \mathrm{N}$ between 1984 and 2003, consistent with the partial rainfall recovery in the region. The spatial distribution of surface albedo changes also showed an overall decrease in surface albedo in this period over the Sahel with the largest differences locally exceeding 0.15 (Figure 6). The authors indicate that, although precipitation is identified as a decisive controlling factor in this greening trend [87], human factors, including among other improved land management, might also explain some local trends [88]. According to the United Nation's definition [83], desertification results from various factors, including climate variations and human activities. It could be expected that the great Sahel drought during the 1970s and the1980s should have substantial impact on the land degradation since even a partial rainfall recovery from 1984 to 2003 could cause a change in albedo for about 0.06 . The specification of albedo change of 0.1 in a desertification impact study [15] showed a significant impact on the regional climate. However, there is an imperative need to incorporate/identify/distinguish the impact of land degradation caused by anthropogenic land use change and regional climate change. A few studies have tackled this issue. For instance, in an off-line modeling study forced by the NCEP reanalysis, d'Orgeval and Polcher [89] suggested that the impact of land-use changes was much less important 
than the impact of precipitation changes over the years 19512000 in large West African catchments' runoff. More studies with coupled models are necessary to further evaluate this issue, especially since this issue is very relevant to the future climate projection.

A number of studies have explored the climate/vegetation relationship in West Africa based on ground survey/ measurements [52, 90]. Rian et al. [90] quantitatively identify strong relationships between vegetation types, LAI, and climate variables (precipitation and surface temperature) and distinguish features in the vegetation/climate transition using the satellite data and field measurements. The study indicates that precipitation differences and the resulting impact on available soil moisture are the main drivers of the land cover transition in this region. The analysis shows the dominant control of summer precipitation on vegetation zonation and structure, with woody savanna being restricted to areas receiving $>1000 \mathrm{~mm}$ mean annual precipitation, the lightly wooded savanna to areas of $>700 \mathrm{~mm}$ precipitation, the dense shrub savanna to areas of $>500 \mathrm{~mm}$ precipitation, and the open and sparse shrub savanna to areas of $>200 \mathrm{~mm}$.

The importance of incorporating two-way vegetation/climate interaction has also been demonstrated in modeling studies, some of which focused on the African paleoclimate [91, 92]. Wang et al. [93] investigated the impact of large-scale oceanic forcing and local vegetation feedback on the variability of the Sahel rainfall using a global biosphereatmosphere model. The study examined the effect of treating vegetation as a dynamic component of the earth climate system rather than a static boundary condition. When vegetation is dynamic, the model realistically reproduces the multidecadal scale fluctuation of rainfall in the Sahel region; keeping vegetation static in the same model results in a rainfall regime characterized by fluctuations at much shorter time scales, indicating that vegetation dynamics acts as a mechanism for persistence of the regional climate. The above-mentioned DVM studies mainly focus on a longterm equilibrium conditions. To study the future climate change and societal planning with enhanced atmospheric $\mathrm{CO}_{2}$ concentration [94-96], application of DVM for short time scales, for instance interannual to decadal time scale, remains a great challenge. Examining the DVMs with local scale/high resolution satellite data and field data is necessary.

Furthermore, to achieve substantial progress in fully coupled atmospheric modeling at meso to regional scales and to improve seasonal prediction and projection of climate change and its impact, as well as understanding the mechanisms involved, it is evident that effort must be made to improve the representation of land surface and hydrological processes which are specific to this region (such as transpiration from very deep layers in the soil, hydrophobic infiltration effects, significant subgrid lateral water transfer) and to provide numerical weather prediction models with more accurate spatial structure in the initialization of soil moisture. This requires the development of techniques to assimilate satellite data pertaining to the land surface, most notably soil moisture, land surface temperature, and vegetation LAI. ALMIP phase 2 is addressing this issue by evaluating an ensemble of LSM and hydrological models at the local to basin (meso) scale using observational data from the AMMA-CATCH transect [11]. However, the example of the study by Agustí-Panareda et al. [97] provides a cautionary note here. In that study, ALMIP-derived soil moisture was used to initialize a series of forecasts and the output compared with the standard soil moisture initialization based on assimilation of screen-level observations. The authors found that the substantial dry bias in Sahel precipitation in their model was rather insensitive to the soil moisture, suggesting that other processes (notably radiation and convection) were dominating. Only when the description of the basic processes which shape the monsoon system are adequately captured by the models may we expect the full value of additional land surface information to improve forecasts.

\section{Acknowledgments}

This research was supported by the US National Science Foundation Grant ATM-0751030. The authors also appreciate Dr. Randy Koster of NASA and Dr. Yves Govaerts of EUMETSAT, Germany, for providing their figures for this paper. The anonymous reviewer provides very constructive and detailed comments/suggestions, which greatly help improving this paper. They really appreciate the reviewer's efforts and contribution.

\section{References}

[1] United Nations Office for West Africa, West Africa, http:// unowa.unmissions.org/Default.aspx?tabid=793.

[2] M. Hulme, "Validation of large-scale precipitation fields in General Circulation Models," in Global Precipitations and Climate Change, M. Desbois and F. Desalmand, Eds., NATO ASI Series, p. 466, Springer, Berlin, Germany, 1994.

[3] S. E. Nicholson, B. Some, and B. Kone, "An analysis of recent rainfall conditions in West Africa, including the rainy seasons of the 1997 El Nino and the 1998 La Nina years," Journal of Climate, vol. 13, no. 14, pp. 2628-2640, 2000.

[4] L. Le Barbé, T. Lebel, and D. Tapsoba, "Rainfall variability in West Africa during the years 1950-1990," Journal of Climate, vol. 15, no. 2, pp. 187-202, 2002.

[5] A. Dai, P. J. Lamb, K. E. Trenberth, M. Hulme, P. D. Jones, and P. Xie, "The recent Sahel drought is real," International Journal of Climatology, vol. 24, no. 11, pp. 1323-1331, 2004.

[6] W. K. M. Lau, K. M. Kim, and M. I. Lee, "Characteristics of diurnal and seasonal cycles in global monsoon systems," Journal of the Meteorological Society of Japan, vol. 85, pp. 403416, 2007.

[7] J. L. Redelsperger, C. D. Thorncroft, A. Diedhiou, T. Lebel, D. J. Parker, and J. Polcher, "African Monsoon Multidisciplinary Analysis: an international research project and field campaign," Bulletin of the American Meteorological Society, vol. 88, no. 12, pp. 1739-1746, 2006.

[8] United Nations, "World Population Prospects," United Nations Publication, pp. 801, 2009.

[9] P. J. Lamb, "Large-scale tropical Atlantic surface circulation patterns associated with sub-Saharan weather anomalies," Tellus, vol. 30, pp. 240-251, 1978.

[10] C. J. Folland, M. Owen, N. Ward, and A. Colman, "Prediction of seasonal rainfall in the Sahel region using empirical and 
dynamical methods," Journal of Forecasting, vol. 1, pp. 21-56, 1991.

[11] T. Lebel, B. Cappelaere, S. Galle et al., "AMMA-CATCH studies in the Sahelian region of West-Africa: an overview," Journal of Hydrology, vol. 375, no. 1-2, pp. 3-13, 2009.

[12] J. Charney, W. J. Quirk, S. H. Chow, and J. Kornfield, "A comparative study of the effects of albedo change on drought in semi-arid regions," Journal of the Atmospheric Sciences, vol. 34, no. 9, pp. 1366-1385, 1977.

[13] K. Laval and L. Picon, "Effect of a change of the surface albedo of the Sahel on climate," Journal of the Atmospheric Sciences, vol. 43, no. 21, pp. 2418-2429, 1986.

[14] Y. Xue, K.-N. Liou, and A. Kasahara, "Investigation of the biophysical feedback on the African climate using a twodimensional model," Journal of Climate, vol. 3, pp. 337-352, 1990.

[15] Y. Xue and J. Shukla, "The influence of land surface properties on Sahel climate. Part I: desertification," Journal of Climate, vol. 6, no. 12, pp. 2232-2245, 1993.

[16] E. A. B. Eltahir and C. Gong, "Dynamics of wet and dry years in West Africa," Journal of Climate, vol. 9, no. 5, pp. 1030-1042, 1996.

[17] C. M. Taylor, E. F. Lambin, N. Stephenne, R. J. Harding, and R. L. H. Essery, "The influence of land use change on climate in the Sahel," Journal of Climate, vol. 15, no. 24, pp. 3615-3629, 2002.

[18] N. Zeng, J. D. Neelin, K. M. Lau, and C. J. Tucker, "Enhancement of interdecadal climate variability in the Sahel by vegetation interaction," Science, vol. 286, no. 5444, pp. $1537-$ 1540, 1999.

[19] G. Wang and E. A. B. Eltahir, "Role of vegetation dynamics in enhancing the low-frequency variability of the Sahel rainfall," Water Resources Research, vol. 36, no. 4, pp. 1013-1021, 2000.

[20] S. Nicholson, "Land surface processes and Sahel climate," Reviews of Geophysics, vol. 38, no. 1, pp. 117-139, 2000.

[21] Y. Xue, R. W. A. Hutjes, R. J. Harding et al., "The Sahelian Climate (Chapter A5)," in Vegetation, Water, Humans and the Climate, P. Kabat, M. Claussen, P. A. Dirmeyer et al., Eds., pp. 59-77, Springer, Berlin, Germany, 2004.

[22] C. M. Taylor, D. J. Parker, N. Kalthoff et al., "New perspectives on land-atmosphere feedbacks from the African Monsoon Multidisciplinary Analysis," Atmospheric Science Letters, vol. 12, pp. 38-44, 2011.

[23] P. Xie and P. A. Arkin, "Global Precipitation: a 17-year monthly analysis based on Gauge observations, satellite estimates, and numerical model outputs," Bulletin of the American Meteorological Society, vol. 78, no. 11, pp. 2539-2558, 1997.

[24] J. P. Goutorbe, A. J. Dolman, J. H. C. Gash et al., HAPEXSahel, Elsevier, Amsterdam, The Netherlands, 1997.

[25] T. Lebel, D. J. Parker, C. Flamant et al., "The AMMA field campaigns: accomplishments and lessons learned," Atmospheric Science Letters, vol. 12, no. 1, pp. 123-128, 2011.

[26] A. Boone, P. de Rosnay, G. Balsamo et al., "The AMMA land surface model intercomparison project (ALMIP)," Bulletin of the American Meteorological Society, vol. 90, no. 12, pp. 18651880, 2009.

[27] G. J. Huffman, R. F. Adler, D. T. Bolvin et al., "The TRMM Multisatellite Precipitation Analysis (TMPA): quasi-global, multiyear, combined-sensor precipitation estimates at fine scales," Journal of Hydrometeorology, vol. 8, no. 1, pp. 38-55, 2007.
[28] B. Geiger, C. Meurey, D. Lajas, L. Franchistéguy, D. Carrer, and J. L. Roujean, "Near real-time provision of downwelling shortwave radiation estimates derived from satellite observations," Meteorological Applications, vol. 15, no. 3, pp. 411-420, 2008.

[29] P. de Rosnay, M. Drusch, A. Boone et al., "AMMA land surface model intercomparison experiment coupled to the community microwave emission model: ALMIP-MEM," Journal of Geophysical Research D, vol. 114, no. 5, Article ID D05108, 2009.

[30] M. Grippa, L. Kergoat, F. Frappart et al., "Land water storage variability over West Africa estimated by Gravity Recovery and Climate Experiment (GRACE) and land surface models," Water Resources Research, vol. 47, no. 5, article W05549, 2011.

[31] F. Timouk, L. Kergoat, E. Mougin et al., "Response of surface energy balance to water regime and vegetation development in a Sahelian landscape," Journal of Hydrology, vol. 375, no. 1-2, pp. 178-189, 2009.

[32] X. Gao and P. A. Dirmeyer, "A multimodel analysis, validation, and transferability study of global soil wetness products," Journal of Hydrometeorology, vol. 7, no. 6, pp. 1218-1236, 2006.

[33] A. A. Boone, I. Poccard-Leclercq, Y. Xue, J. Feng, and P. de Rosnay, "Evaluation of the WAMME model surface fluxes using results from the AMMA land-surface model intercomparison project," Climate Dynamics, vol. 35, no. 1, pp. 127-142, 2010.

[34] P. Tulet, M. Mallet, V. Pont et al., “The 7-12 March dust storm over West Africa: mineral dust generation and vertical layering in the atmosphere," Journal of Geophysical Research, vol. 113, article D00C08, 13 pages, 2008.

[35] C. Kocha, J. P. Lafore, P. Tulet, and Y. Seity, "High-resolution simulation of a major West African dust-storm: comparison with observations and investigation of dust impact," Quarterly Journal of the Royal Meteorological Society, vol. 138, no. 663, pp. 455-470, 2012.

[36] C. Delon, C. Galy-Lacaux, A. Boone et al., "Atmospheric nitrogen budget in Sahelian dry savannas," Atmospheric Chemistry and Physics, vol. 10, no. 6, pp. 2691-2708, 2010.

[37] A. Agustí-Panareda, G. Balsamo, and A. Beljaars, "Impact of improved soil moisture on the ECMWF precipitation forecast in West Africa," Geophysical Research Letters, vol. 37, no. 20, Article ID L20808, 2010.

[38] F. Guichard, N. Asencio, C. Peugeot et al., "An intercomparison of simulated rainfall and evapotranspiration associated with a mesoscale convective system over West Africa," Weather and Forecasting, vol. 25, no. 1, pp. 37-60, 2010.

[39] A. L. Steiner, J. S. Pal, S. A. Rauscher et al., "Land surface coupling in regional climate simulations of the West African monsoon," Climate Dynamics, vol. 33, no. 6, pp. 869-892, 2009.

[40] F. Hourdin, F. Guichard, I. Musat et al., "AMMA-Model intercomparison project," Bulletin of the American Meteorological Society, vol. 91, no. 1, pp. 95-104, 2010.

[41] R. Meynadier, O. Bock, F. Guichard, A. Boone, P. Roucou, and J. L. Redelsperger, "West African Monsoon water cycle: 1. A hybrid water budget data set," Journal of Geophysical Research D, vol. 115, no. 19, Article ID D19106, 2010.

[42] Y. Xue, F. de Sales, W. K. M. Lau et al., "Intercomparison and analyses of the climatology of the West African Monsoon in the West African Monsoon Modeling and Evaluation project (WAMME) first model intercomparison experiment," Climate Dynamics, vol. 35, no. 1, pp. 3-27, 2010.

[43] N. Martiny, Y. Richard, and P. Camberlin, "Interannual persistence effects in vegetation dynamics of semi-arid Africa," 
Geophysical Research Letters, vol. 32, no. 24, Article ID L24403, 4 pages, 2005

[44] X. Zhang, M. A. Friedl, C. B. Schaaf, A. H. Strahler, and Z. Liu, "Monitoring the response of vegetation phenology to precipitation in Africa by coupling MODIS and TRMM instruments," Journal of Geophysical Research D, vol. 110, no. 12, Article ID D12103, 14 pages, 2005.

[45] Z. Liu, M. Notaro, J. Kutzbach, and N. Liu, "Assessing global vegetation-climate feedbacks from observations," Journal of Climate, vol. 19, no. 5, pp. 787-814, 2006.

[46] S. O. Los, G. P. Weedon, P. R. J. North, J. D. Kaduk, C. M. Taylor, and P. M. Cox, "An observation-based estimate of the strength of rainfall-vegetation interactions in the Sahel," Geophysical Research Letters, vol. 33, no. 16, Article ID L16402, 2006.

[47] X. Zeng, P. Rao, R. S. DeFries, and M. C. Hansen, "Interannual variability and decadal trend of global fractional vegetation cover from 1982 to 2000," Journal of Applied Meteorology, vol. 42, no. 10, pp. 1525-1530, 2003.

[48] L. Jarlan, Y. M. Tourre, E. Mougin, N. Philippon, and P. Mazzega, "Dominant patterns of AVHRR NDVI interannual variability over the Sahel and linkages with key climate signals (1982-2003)," Geophysical Research Letters, vol. 32, no. 4, Article ID L04701, 4 pages, 2005.

[49] N. Philippon, L. Jarlan, N. Martiny, P. Camberlin, and E. Mougin, "Characterization of the interannual and intraseasonal variability of West African vegetation between 1982 and 2002 by means of NOAA AVHRR NDVI data," Journal of Climate, vol. 20, no. 7, pp. 1202-1218, 2007.

[50] L. Eklundh and L. Olsson, "Vegetation index trends for the African Sahel 1982-1999," Geophysical Research Letters, vol. 30, no. 8, Article ID 1430, 4 pages, 2003.

[51] Y. Govaerts and A. Lattanzio, "Estimation of surface albedo increase during the eighties Sahel drought from Meteosat observations," Global and Planetary Change, vol. 64, no. 3-4, pp. 139-145, 2008.

[52] P. Hiernaux, L. Diarra, V. Trichon, E. Mougin, N. Soumaguel, and F. Baup, "Woody plant population dynamics in response to climate changes from 1984 to 2006 in Sahel (Gourma, Mali)," Journal of Hydrology, vol. 375, no. 1-2, pp. 103-113, 2009.

[53] R. D. Koster, P. A. Dirmeyer, Z. Guo et al., "Regions of strong coupling between soil moisture and precipitation," Science, vol. 305, no. 5687, pp. 1138-1140, 2004.

[54] H. Douville, F. Chauvin, and H. Broqua, "Influence of soil moisture on the Asian and African monsoons. Part I: mean monsoon and daily precipitation," Journal of Climate, vol. 14, no. 11, pp. 2381-2403, 2001.

[55] H. Douville, "Influence of soil moisture on the Asian and African monsoons. Part II: interannual variability," Journal of Climate, vol. 15, no. 7, pp. 701-720, 2002.

[56] P. A. Dirmeyer, A. J. Dolman, and N. Sato, "The pilot phase of the global soil wetness project," Bulletin of the American Meteorological Society, vol. 80, no. 5, pp. 851-878, 1999.

[57] M. Notaro, "Statistical identification of global hot spots in soil moisture feedbacks among IPCC AR4 models," Journal of Geophysical Research D, vol. 113, no. 9, Article ID D09101, 2008.

[58] N. Philippon and B. Fontaine, "The relationship between the Sahelian and previous 2nd Guinean rainy seasons: a monsoon regulation by soil wetness?" Annales Geophysicae, vol. 20, no. 4, pp. 575-582, 2002.

[59] M. Shinoda and Y. Yamaguchi, "Influence of soil moisture anomaly on temperature in the Sahel: a comparison between wet and dry decades," Journal of Hydrometeorology, vol. 4, no. 2, pp. 437-447, 2003.

[60] H. Douville, S. Conil, S. Tyteca, and A. Voldoire, "Soil moisture memory and West African monsoon predictability: artefact or reality?" Climate Dynamics, vol. 28, no. 7-8, pp. 723-742, 2007.

[61] B. J. J. M. van den Hurk and E. van Meijgaard, "Diagnosing land-atmosphere interaction from a regional climate model simulation over West Africa," Journal of Hydrometeorology, vol. 11, no. 2, pp. 467-481, 2010.

[62] Y. Xue, F. De Sales, R. Vasic et al., "Global and temporal characteristics of seasonal climate/vegetation biophysical process (VBP) interactions," Journal of Climate, vol. 23, pp. 14111433, 2010.

[63] H. S. Kang, Y. Xue, and G. J. Collatz, "Impact assessment of satellite-derived leaf area index datasets using a general circulation model," Journal of Climate, vol. 20, no. 6, pp. 9931015, 2007.

[64] Y. Xue, H. M. H. Juang, W. P. Li et al., "Role of land surface processes in monsoon development: East Asia and West Africa," Journal of Geophysical Research D, vol. 109, no. 3, Article ID D03105, 24 pages, 2004.

[65] C. M. Taylor, "Intraseasonal land-atmospheric coupling in the West African monsoon," Journal of Climate, vol. 21, no. 24, pp. 6636-6648, 2008.

[66] S. L. Lavender, C. M. Taylor, and A. J. Matthews, "Coupled land-atmosphere intraseasonal variability of the West African monsoon in a GCM," Journal of Climate, vol. 23, no. 21, pp. 5557-5571, 2010.

[67] K. H. Cook, "Generation of the African easterly jet and its role in determining West African precipitation," Journal of Climate, vol. 12, no. 5, pp. 1165-1184, 1999.

[68] C. D. Thorncroft and M. Blackburn, "Maintenance of the African easterly jet," Quarterly Journal of the Royal Meteorological Society, vol. 125, no. 555, pp. 763-786, 1999.

[69] W. Li, Y. Xue, and I. Poccard, "Numerical investigation of the impact of vegetation indices on the variability of West African summer monsoon," Journal of the Meteorological Society of Japan, vol. 85, pp. 363-383, 2007.

[70] M. L. C. Wu, O. Reale, S. D. Schubert, M. J. Suarez, R. D. Koster, and P. J. Pegion, "African easterly jet: structure and maintenance," Journal of Climate, vol. 22, no. 17, pp. 44594480, 2009.

[71] S. D. Prince, Y. H. Kerr, J. P. Goutorbe et al., "Geographical, biological and remote sensing aspects of the hydrologic atmospheric pilot experiment in the Sahel (HAPEX-Sahel)," Remote Sensing of Environment, vol. 51, no. 1, pp. 215-234, 1995.

[72] M. Kohler, N. Kalthoff, and C. Kottmeier, "The impact of soil moisture modifications on CBL characteristics in West Africa: a case-study from the AMMA campaign," Quarterly Journal of the Royal Meteorological Society, vol. 136, no. 1, pp. 442-455, 2010.

[73] C. M. Taylor, D. J. Parker, and P. P. Harris, "An observational case study of mesoscale atmospheric circulations induced by soil moisture," Geophysical Research Letters, vol. 34, no. 15, Article ID L15801, 2007.

[74] L. Garcia-Carreras, D. J. Parker, C. M. Taylor, C. E. Reeves, and J. G. Murphy, "Impact of mesoscale vegetation heterogeneities on the dynamical and thermodynamic properties of the planetary boundary layer," Journal of Geophysical Research D, vol. 115, no. 3, Article ID D03102, 2010.

[75] M. A. Gaertner, M. Domínguez, and M. Garvert, "A modelling case-study of soil moisture-atmosphere coupling," Quarterly 
Journal of the Royal Meteorological Society, vol. 136, no. 1, pp. 483-495, 2010.

[76] L. Gantner and N. Kalthoff, "Sensitivity of a modelled life cycle of a mesoscale convective system to soil conditions over West Africa," Quarterly Journal of the Royal Meteorological Society, vol. 136, no. 1, pp. 471-482, 2010.

[77] C. M. Taylor, A. Gounou, F. Guichard et al., "Frequency of sahelian storm initiation enhanced over mesoscale soil-moisture patterns," Nature Geoscience, vol. 4, no. 7, pp. 430-433, 2011.

[78] C. M. Taylor, "Feedbacks on convection from an African wetland," Geophysical Research Letters, vol. 37, article L05406, 2010.

[79] H. F. Lamprey, "Report on the desert encroachment reconnaissance in northern Sudan," Desertification Control Bulletin, vol. 17 , pp. $1-7,1988$.

[80] C. J. Tucker and S. E. Nicholson, "Variations in the size of the Sahara Desert from 1980 to 1997," Ambio, vol. 28, no. 7, pp. 587-591, 1999.

[81] A. J. Pitman, N. De Noblet-Ducoudré, F. T. Cruz et al., "Uncertainties in climate responses to past land cover change: first results from the LUCID intercomparison study," Geophysical Research Letters, vol. 36, no. 14, Article ID L14814, 2009.

[82] H. E. Dregne and N. T. Chou, "Global desertification dimensions and costs," in Degradation and Restoration of Arid Lands, pp. 249-282, Texas Tech University, 1992.

[83] N. Middleton, The Global Casino. An Introduction to Environmental Issues, Arnold, 4th edition, 2008.

[84] A. S. Goudie, The Human Impact on the Natural Environment, The MIT Press, 6th edition, 2006.

[85] P. Hiernaux, A. Ayantunde, A. Kalilou et al., "Trends in productivity of crops, fallow and rangelands in Southwest Niger: impact of land use, management and variable rainfall," Journal of Hydrology, vol. 375, no. 1-2, pp. 65-77, 2009.

[86] G. C. Hurtt, S. Frolking, M. G. Fearon et al., "The underpinnings of land-use history: three centuries of global gridded land-use transitions, wood-harvest activity, and resulting secondary lands," Global Change Biology, vol. 12, no. 7, pp. 1208-1229, 2006.

[87] T. Hickler, L. Eklundh, J. W. Seaquist et al., "Precipitation controls Sahel greening trend," Geophysical Research Letters, vol. 32, no. 21, Article ID L21415, 4 pages, 2005.

[88] C. Reij, G. Tappan, and A. Belemvire, "Changing land management practices and vegetation on the Central Plateau of Burkina Faso (1968-2002)," Journal of Arid Environments, vol. 63, no. 3, pp. 642-659, 2005.

[89] T. d'Orgeval and J. Polcher, "Impacts of precipitation events and land-use changes on West African river discharges during the years 1951-2000," Climate Dynamics, vol. 31, no. 2-3, pp. 249-262, 2008.

[90] S. Rian, Y. Xue, G. M. MacDonald et al., "Analysis of climate and vegetation characteristics along the savannadesert ecotone in mali using MODIS data," GIScience and Remote Sensing, vol. 46, no. 4, pp. 424-450, 2009.

[91] S. Levis, G. B. Bonan, and C. Bonfils, "Soil feedback drives the mid-Holocene North African monsoon northward in fully coupled CCSM2 simulations with a dynamic vegetation model," Climate Dynamics, vol. 23, no. 7-8, pp. 791-802, 2004.

[92] M. Notaro, Y. Wang, Z. Liu, R. Gallimore, and S. Levis, "Combined statistical and dynamical assessment of simulated vegetation-rainfall interactions in North Africa during the mid-Holocene," Global Change Biology, vol. 14, no. 2, pp. 347368,2008 .
[93] G. Wang, E. A. B. Eltahir, J. A. Foley, D. Pollard, and S. Levis, "Decadal variability of rainfall in the Sahel: results from the coupled GENESIS-IBIS atmosphere-biosphere model," Climate Dynamics, vol. 22, no. 6-7, pp. 625-637, 2004.

[94] G. Wang and E. A. B. Eltahir, "Impact of $\mathrm{CO}_{2}$ concentration changes on the biosphere-atmosphere system of West Africa," Global Change Biology, vol. 8, no. 12, pp. 1169-1182, 2002.

[95] C. A. Alo and G. Wang, "Role of dynamic vegetation in regional climate predictions over Western Africa," Climate Dynamics, vol. 35, no. 5, pp. 907-922, 2010.

[96] H. Paeth, K. Born, R. Girmes, R. Podzun, and D. Jacob, "Regional climate change in tropical and Northern Africa due to greenhouse forcing and land use changes," Journal of Climate, vol. 22, no. 1, pp. 114-132, 2009.

[97] A. Agustí-Panareda, G. Balsamo, and A. Beljaars, "Impact of improved soil moisture on the ECMWF precipitation forecast in West Africa," Geophysical Research Letters, vol. 37, no. 20, Article ID L20808, 2010. 

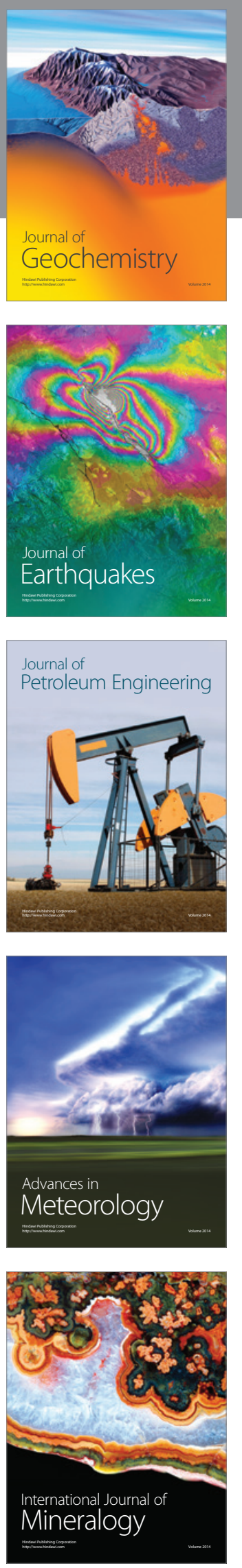
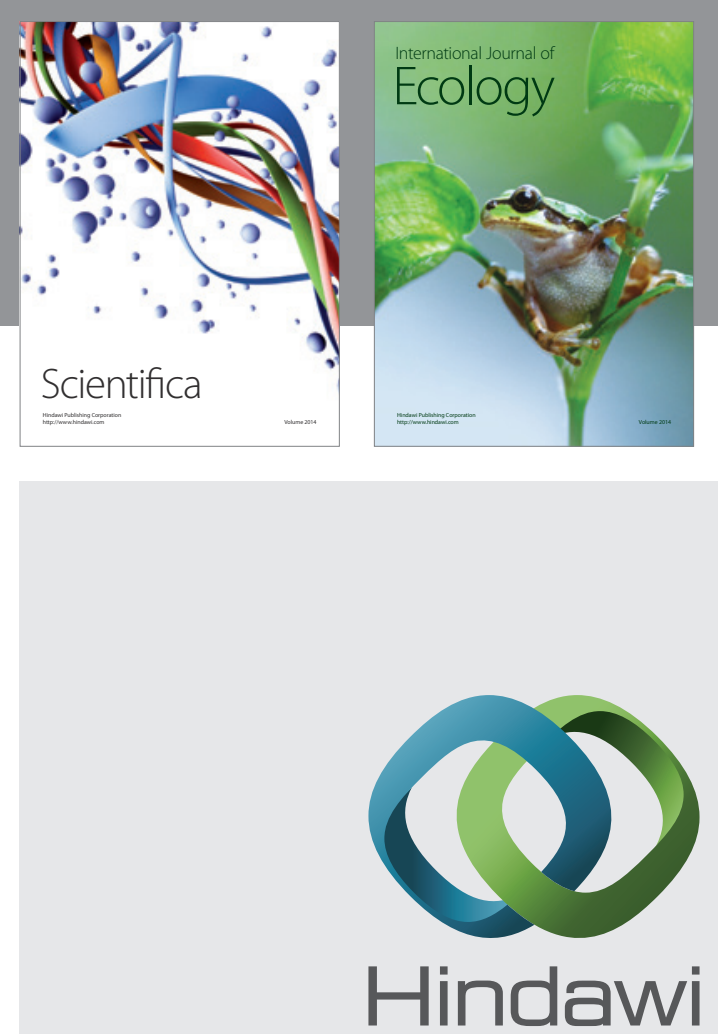

Submit your manuscripts at http://www.hindawi.com
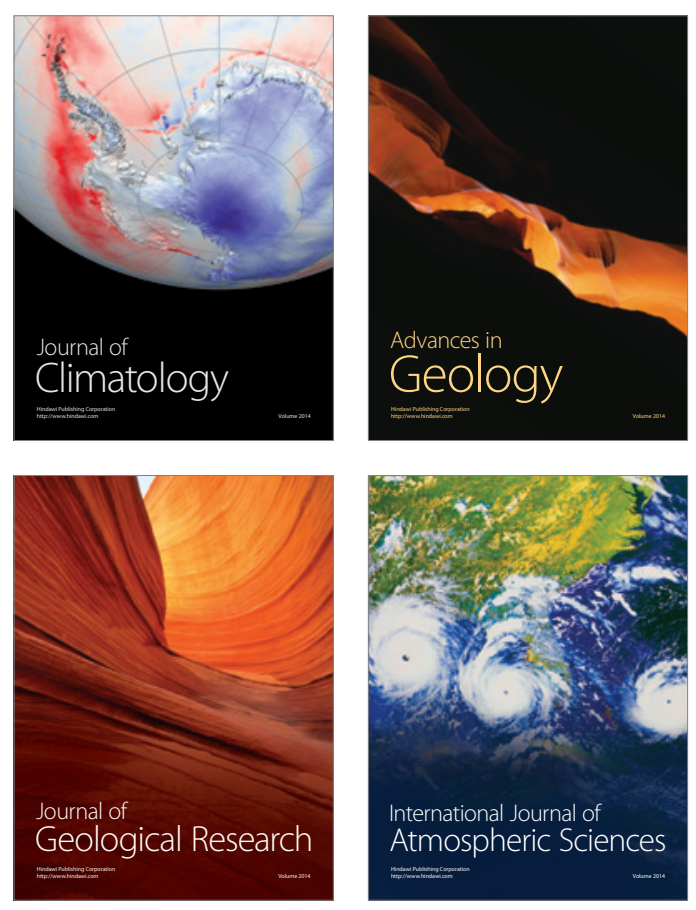
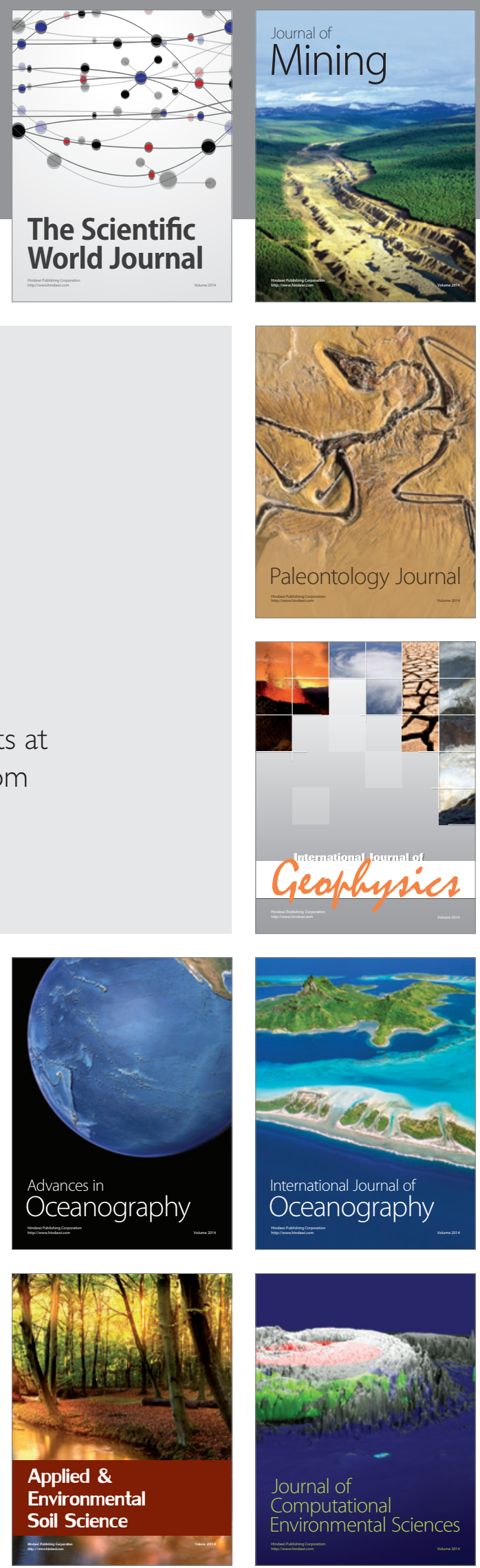